\title{
El guardagujas de Juan José Arreola, visto a través del Principio de incertidumbre ${ }^{\prime}$
}

\author{
The Uncertainty Principle in “The Switchman” by Juan José Arreola
}

\author{
IRAM ISAÍ EVANGELISTA ÁVILA \\ CÉSAR GUILLERMO GARCÍA GONZÁLEZ \\ JESÚS ERBEY MENDOZA NEGRETE \\ Universidad Autónoma de Chihuahuaa \\ México \\ ievangelista@uach.mx \\ cgarciag@uach.mx \\ mendozaerbey@gmail.com
}

(Recibido: 05-08-2020; aceptado: II-II-2O2O)

Resumen. El presente trabajo propone una lectura de "El guardagujas" de Juan José Arreola desde el concepto del "principio de incertidumbre" utilizado en Economía. La incertidumbre aparece en la trama del cuento como un tipo de antagonista que pone en estado de alerta al protagonista ante el devenir de la vida. Juan José Arreola utiliza la disposición de su texto de una manera simbólica, plasmando a la vez los rasgos característicos de su escritura. A pesar de la evidente distancia entre las disciplinas, el principio de incertidumbre que propone la economía resulta adecuado en el abordaje de esta obra literaria ya que permite una lectura que, lejos de contradecir otras interpretaciones, las enriquece. Así, el principio economista (Nieto de Alba, 1989) es trasladado hacia el análisis literario según las pautas que sugiere la metáfora narrativa (Garayalde, 2018). De esta manera, encontramos que el estado de incertidumbre, además de ser el detonante de la trama, funciona como un catalizador positivo al momento de tomar decisiones. Palabras clave: principio de incertidumbre; indeterminación; narrativa; decisión.
Abstract. The following paper formulates an interpretation of the story "The Switchman" by Juan José Arreola, as seen through the "uncertainty principle" used in Economics. The uncertainty is shown in the plot of the story as a kind of antagonist that places the main character in a state of alert in the face of life. Juan José Arreola uses the arrangement of his text in a symbolic way, reflecting at the same time the distinctive traits of his writing. Despite the evident distance between the fields involved, the uncertainty principle in Economics proves adequate in this discussion since it enables an interpretation that, rather than contradicting previous interpretations, enriches their contribution. The principle derived from Economics (Nieto de Alba, 1989) will be, then, transferred into literary analysis following the guidelines suggested by the narrative metaphor (Garayalde, 2018). Thus, the uncertainty state, besides being the plot trigger, works as a positive catalyst when making decisions.

Keywords: uncertainty principle; indetermination; fiction; decision.

\footnotetext{
${ }^{\text {I }}$ Para citar este artículo: Evangelista Ávila, Iram Isaí; García Gonzáles, César Guillermo y Mendoza Negrete, Jesús Erbey (2O2I). El guardagujas de Juan José Arreola, visto a través del Principio de incertidumbre. Alabe 23 . [www.revistaalabe.com] DÖI: IO.I5645/Alabe2O2I.23.2
} 


\section{Arreola en las vías de la interpretación}

Juan José Arreola, escritor jalisciense nacido el 2i de septiembre de I9I8, fue autodidacta y tuvo varios oficios, desde vendedor de zapatos a catedrático de la Universidad Nacional Autónoma de México. En su taller de escritores surgieron varias figuras literarias tales como José Emilio Pacheco y Elsa Cross. Confabulario se publica en I952 donde aparece "El guardagujas". Julio Cortázar describe a Arreola y su creación de la siguiente manera: “Usted es una hormiga león, si son las hormigas león las que hacen un embudo en la arena para que sus víctimas resbalen al fondo. Cuatro palabras y zas, adentro. Pero vale la pena ser comido por usted” (Arreola, ı998: 292). También, Felipe Vázquez, menciona lo siguiente sobre la escritura de "El último juglar": "Como un alquimista, transmutó con gracia varios géneros y propuso una nueva forma, al mismo tiempo extraña y familiar" (20I3: 88). Así, el cuento "El guardagujas" versa sobre un forastero que llega a una estación de tren y es sorprendido por el personaje del guardagujas. El extranjero menciona que debe llegar a la estación de "T." y que debe partir justo ahora en el tren para poder llegar a su destino. El ferroviario menciona que en esa estación los trenes no obedecen a un itinerario o a un destino fijo y que es mejor comprar muchos boletos para ver si algún día -tal vez en la próxima salida- pueda llegar a su destino (Arreola, 2006: 77). Dentro del cuento, la incertidumbre posee una acción preponderante en la trama. De hecho, el propio país es un lugar donde todos sus habitantes se encuentran inmersos en esta dinámica. El personaje del forastero se caracteriza por poseer un carácter metódico y disciplinado, encaminado a encontrar objetividad en su vida; su itinerario está definido, sus tiempos y juicios están ya estudiados e impuestos. No obstante, se enfrenta a que su trayecto puede estar lleno de circunstancias e indeterminaciones, las cuales son desplegadas y descritas a través de las intervenciones del guardagujas jubilado. El personaje del ferroviario es una fuerza independiente y todo el país vive en la espontaneidad. El visitante posee una objetividad determinante, las probabilidades no figuran en su sistema el cual comienza a fracturarse. Las propuestas que el guardavía le presenta no encajan en su plan maquinalmente detallado pues su modo de vida es directo y tajante; no hay bifurcaciones.

Juan José Arreola es un autor que dentro de la trama de sus cuentos maneja un lenguaje fértil para la interpretación. El trabajo a continuación tiene como objetivo desarrollar una lectura de "El guardagujas" desde la perspectiva del concepto de incertidumbre. Se mostrará cómo esta juega un rol primordial dentro del relato. Este estado acompaña a los protagonistas durante su travesía dentro de la trama y los encamina a situaciones desconocidas donde la acción se precipita a lo indeterminado. Cabe señalar que esta recreación de la indeterminación puede fomentar en el lector a adquirir capacidades de asimilar la incertidumbre como un tránsito necesario para afrontar las posibles contingencias en su andar.

El orden que presentará el trabajo será el siguiente: primero, presentación, delimitación y extrapolación del concepto de incertidumbre. Segundo, aplicaremos el 
concepto de incertidumbre en la interpretación de las acciones y los personajes dentro de la trama del cuento. Finalmente, evidenciaremos cómo a través de determinados diálogos, el personaje de "el forastero", va encaminándose al cambio de paradigma o la aceptación de lo indeterminado como parte de su vida.

\section{El principio de incertidumbre}

El principio de incertidumbre fue postulado por el físico alemán Werner Heisenberg. Desde dicho principio se señala que:

En microfísica, en la observación de la realidad (partícula) el observador influye en lo observado (velocidad y posición de la partícula) haciendo imposible determinar ambos (posición y velocidad). Esto nos conduce a un cambio de visión de la realidad, ya que el observador influye en el curso de la realidad que observa (Nieto de Alba, I989: I8).

Ubaldo Nieto de Alba explica que el hombre es partícipe de la existencia en dos planos: como actor y como espectador, y que esta acción que se toma, entonces, influye en los actos posteriores; por ello, el presente no es determinante en lo que suceda con lo futuro. Lo anterior abre paso a la probabilidad sobre la certidumbre, lo biológico sobre lo mecanista (I989: I9). Para Nieto de Alba, al incluir este concepto en economía se revalora la acción de los actores y los despoja de una atribución de perfección a una dinámica más humana: "La incertidumbre priva al individuo de su omnisciencia haciéndole impotente para el conocimiento cierto del futuro, pero refuerza su poder sobre la naturaleza” (40). Y enfatiza con ello la cualidad en las acciones humanas:

Desde el momento en que introducimos la incertidumbre estamos abriendo el camino de la acción humana, de una acción humana inmersa en un pluralismo social, donde no solamente hay libertad y competencia, sino también cooperación y solidaridad. Si la incertidumbre no nos permite conocer el futuro, nos obligará a pensar en lo que dicho futuro debería ser (1989:4I).

Esta perspectiva es claramente aplicable a nuestro abordaje. Pero no podemos solamente incluir terminologías y esperar que los resultados sean una copia de su antecesor; por el contrario, se espera que los resultados sean diferentes. Trabajamos entonces con las similitudes de las propuestas que nos puedan ayudar a analizar nuestro texto literario. El Dr. Nieto añade: "No se trata, en definitiva, de invalidar teorías y sustituirlas por otras; cada una permanece válida en un campo bien definido" (I989: 4I). Esto nos da la pauta para analizar la narrativa arreolina en tanto a las situaciones 
por las cuales transitan los personajes, la manera en cómo interaccionan al momento de encontrarse en incertidumbre y cómo, dentro de este estadio, se fraguan las decisiones que toman para continuar dentro del transcurso de la obra.

\section{I. Aproximaciones al concepto de incertidumbre}

Gil, Pérez y Urtasun (2OI7) sostienen que la actividad de los agentes económicos se realiza siempre en un contexto de incertidumbre. Las familias, las empresas y los Gobiernos tienen que adoptar decisiones de gasto o inversión, lo que conlleva a elaborar ciertas hipótesis sobre la evolución futura de determinadas variables y la asignación -subjetiva u objetiva- de probabilidad a los distintos estados de la naturaleza, en la medida en que estos puedan identificarse. Múltiples decisiones se realizan sin conocer las consecuencias exactas que estas impliquen. En este caso se deben hacer supuestos especiales que nos permitan aproximarnos a las preferencias de los agentes acerca de los bienes de los que no tienen conocimiento perfecto de sus características. La teoría básica es la propuesta por Von Neumann y Morgenstern y que se denomina “teoría de la utilidad esperada". Según su definición, la incertidumbre se entiende como una función de probabilidad definida sobre los posibles valores de las variables inciertas y que los individuos deciden según la alternativa que les brinda mayor utilidad esperada (Plata, Mejía y Accinelli, 2009).

Kliesen (2OI3) expone que la incertidumbre y sus efectos en la toma de decisiones en los negocios a menudo se estudian en el contexto de las motivaciones de expansión o crecimiento de las empresas. Refiere, además, que el vínculo entre la incertidumbre y el beneficio se refinó aún más mediante la introducción del concepto de riesgo. Para algunas personas, el riesgo y la incertidumbre parecen ser lo mismo; sin embargo, esta perspectiva plantea una distinción sutil. La diferencia entre riesgo e incertidumbre fue discutida hace casi Ioo años por el economista Frank Knight.

Según Knight:

Hay una distinción fundamental entre la recompensa por tomar un riesgo conocido y la de asumir un riesgo cuyo valor en sí mismo no se conoce. Es tan fundamental, de hecho, que, un riesgo conocido no conducirá a ninguna recompensa o pago especial a todos (I964: 43-44).

Lo que el autor refiere es que el resultado desfavorable de un riesgo conocido puede ser asegurado durante el proceso de toma de decisiones porque tiene una distribución bien definida de probabilidades esperadas Sin embargo, un riesgo desconocido no tiene una distribución conocida de probabilidades esperadas. La caracterización de Knight del riesgo desconocido ha sido posteriormente denominada "incertidumbre knightiana". Precisamente este "riesgo desconocido", afecta e incide en un cambio significativo en la vida de los personajes inmiscuidos.

También Kliesen (20I3) apunta que uno de los primeros intentos de modelar 
rigurosamente los efectos de la incertidumbre en la inversión empresarial fue publicado por Ben Bernanke en I983. En su análisis, señala que los factores de nivel macro como los cambios inesperados en los precios del petróleo, los cambios en las políticas monetarias y fiscales, o el advenimiento de las nuevas tecnologías son importantes a nivel micro, es decir, afectan las decisiones de una empresa para invertir. Esta decisión adquiere mayor importancia para los proyectos de inversión de largo plazo cuya suspensión sería altamente costosa.

\subsection{Expectativas racionales}

A mediados de los años setenta se empezó a utilizar un nuevo enfoque llamado expectativas racionales, el cual fue propuesto por la corriente de pensamiento "Nueva Economía Clásica”. El supuesto básico de este modelo es que la gente aprende de sus propios errores. Si los errores presentan un sesgo sistemático, los agentes son capaces de corregirlo para hacer predicciones más exactas. Las predicciones pueden seguir siendo erróneas, pero esos errores ya no serán sistemáticos sino aleatorios. El supuesto de la racionalidad de las expectativas es interpretado a veces de forma equivocada como una pretensión de que las previsiones de los agentes son siempre acertadas; es una interpretación equivocada; si las expectativas de los agentes son racionales, seguirán cometiendo errores, pero diferentes en cada ocasión.

La teoría de las expectativas racionales, propuesta por John F. Muth y desarrollada por Robert Lucas -ambos de la escuela de Chicago- junto con Thomas J. Sargent, de Minnesota, señala algunos puntos importantes de muchas de las explicaciones macroeconómicas de su época, basadas en la percepción del futuro por los agentes económicos. Como ya se señaló, el supuesto de este modelo es que las personas aprenden de sus propios errores, las predicciones del público pueden ser erradas, pero sus errores no son sistemáticos sino casuales. Por ejemplo, si esperan un aumento de la inflación los agentes económicos tenderán a ajustar los salarios y los precios de manera que se produzca un alza general de precios, por lo que la política económica debería generar expectativas que, en vez de generar mayores presiones inflacionarias o deflacionarias, induzcan a la estabilidad.

\subsection{Expectativas adaptativas}

Por otra parte, en el análisis económico existe el enfoque de expectativas adaptativas, cuyo principal postulado señala que los agentes económicos basan sus decisiones en datos históricos. Este enfoque se contrapone al de las expectativas racionales previamente expuesto. Según las expectativas adaptativas los agentes económicos fundan sus decisiones en el resultado de actos pasados; sin embargo, en algunas ocasiones no vislumbran sucesos ulteriores.

En ese sentido, el sitio web Polinomics (20I7) esboza que los modelos basados en expectativas adaptativas son formas de predecir el comportamiento de los individuos ante un evento, basándose en experiencias y expectativas pasadas de ese mismo evento. 
Estos modelos fueron utilizados por primera vez por Irving Fisher en su libro The Purchasing Power of Money -Elpoder adquisitivo del dinero-, de I9II, y posteriormente desarrollados en las décadas de los cuarenta y cincuenta especialmente por Phillip Cagan en su artículo "The Monetary Dynamics of Hyper-Inflation” -“La dinámica monetaria de la hiperinflación”-, de 1956 y, más célebremente por Milton Friedman en I957, en su libro A Theory of the Consumption Function-Teoría sobre la función de consumo-.

\section{Modelo de análisis}

Ahora, ¿cómo podemos extrapolar el concepto de incertidumbre hacia el análisis literario? Esteban Garayalde, en su artículo "Transferencia interdisciplinar", nos menciona dos fundamentos que deben tomarse en cuenta para que el concepto de una disciplina pueda aplicarse a otra. El primero es el de "narración metafórica", y el segundo "evitar un vaciamiento del concepto de origen". Veamos el primer postulado:

Llamamos narración metafórica a este proceso a través del cual el desplazamiento de un concepto de una disciplina a otra efectúa un trabajo hermenéutico que permite visibilizar aspectos problemáticos en la disciplina de destino a la vez que ésta última se defiende -para usar un término ligado a una estrategia- por medio de un trabajo poético que trastoca la identidad del concepto y afecta su poder reproductivo (2OI8: IO4).

Al trasladar el concepto de la disciplina inicial -Economía- a una huésped Literatura-, este se envuelve en una interpretación que reconfigura su acción disciplinar, pero que lleva dentro de sí, la configuración necesaria de la primera para que esta pueda ser partícipe de su "esencia” en la disciplina huésped. Este es el comienzo de una construcción interdisciplinar de un concepto, lo cual arrojará resultados nuevos dentro del análisis literario propuesto.

¿Por qué el principio de incertidumbre? Nos enfocamos en este concepto debido a que esta disposición se presenta como una encrucijada, tanto en el ámbito de la Economía como en el literario.

La incertidumbre es un elemento ineludible de la existencia humana. Está en la misma raíz de la finitud humana, la mortalidad y la ignorancia. El papel de la existencia humana hay que jugarlo frente a lo desconocido, en el ámbito de la incertidumbre, como una aventura de decisión sobre el filo de la libertad y la necesidad (Nieto, I989: 7). 
Ya que el personaje del forastero de Arreola se enfrenta con múltiples decisiones de las cuales desconoce sus consecuencias exactas, él debe fabricar supuestos que le permitan replantearse la forma en la que se enfrentará en adelante a su propia vida.

La incertidumbre juega un papel definitivo en la toma de decisiones y, particularmente, en aquellas que dan como resultado consecuencias que afectan directamente a la persona. Como se dijo anteriormente, el ser humano -las familias, las empresas y los Gobiernos, etc.- tiene que adoptar decisiones que afectarán de una u otra manera el transcurso de su vida, lo que conlleva elaborar ciertas hipótesis sobre la evolución futura de determinadas variables y la asignación -subjetiva u objetiva- de probabilidad a los distintos estados de la naturaleza, en la medida en que estos puedan identificarse. Añadiremos que las decisiones de los agentes se encuentran influidas por factores de carácter no solo personales, sino también externo. Esto se asemeja a la definición tradicional que acuña Heisenberg.

Por otro lado, la incertidumbre se ha tomado como algo que debemos evitar a toda costa; no obstante, ejerce un papel preponderante en las situaciones adecuadas para supervivir y encarar diferentes aspectos en la vida. Por ello, se busca aplicar este principio en la narrativa de Juan José Arreola, ya que sus personajes se encuentran inmersos en estados de incertidumbre que involucran y afectan su peregrinar por la trama. Asimismo, creemos que una de las tareas de la literatura es brindar al lector escenarios recreados o representados que lo auxilien en la toma de decisiones. Entendemos estos escenarios literarios a manera de recreaciones de acciones humanas ${ }^{2}$; estas recreaciones o representaciones, a su vez, pueden desarrollar cuasi juicios. Así, la literatura cumple con otro propósito, el de ayudar al lector a refigurar la acción creativa y brindar reflexiones que lo apoyen en su andar por el mundo.

El segundo postulado, "evitar un vaciamiento del concepto de origen", consiste en dos pasos:

I) Comenzar por una definición del concepto literal -es decir, tal y como es formulado en su contexto de origen- que permita establecer un conjunto de atributos que mantendremos durante la transferencia; 2) analizar la pertinencia teórico-epistemológica del concepto metafórico (Garayalde, 20I8: Iog).

Con lo anterior presentaremos la definición que tiene la disciplina de Economía del concepto de incertidumbre, para después analizar sobre cuáles son los rubros de dicho concepto que intervienen o que son pertinentes para el estudio de la literatura.

\footnotetext{
${ }^{2}$ Esta “recreación o representación de las acciones humanas", lo tomamos como Paul Ricœeur explica en Tiempo y narración I, su concepto de: "Mímesis: dígase imitación o representación, lo que hay que entender es la actividad mimética, el proceso activo de imitar o de representar" (2009: 83); “imitar o representar la acción es, en primer lugar, comprender previamente en qué consiste el obrar humano: su semántica su realidad simbólica, su temporalidad. Sobre esta precomprensión, común al poeta y a su lector, se levanta la construcción de la trama y, con ella, la mimética textual y literaria" (I29).
} 
Entonces, basándonos en estas dos guías que nos brinda Garayalde entenderemos el concepto de incertidumbre como las situaciones donde "a lo sumo podemos enumerar los escenarios posibles pero sin ser capaces de medir la posibilidad de su ocurrencia en términos probabilistas" (Rodríguez, 2003: I43). Además, existen tres tipos de "incertidumbre de consecuencias":

I) Conocemos las posibles consecuencias de las distintas opciones pero sólo tenemos un conocimiento incompleto de las probabilidades -"toma de decisiones bajo incertidumbre"-; 2) conocemos las posibles consecuencias de las distintas opciones pero solamente podemos decir de las probabilidades que son no-cero -“toma de decisiones bajo ignorancia”-; 3) Las posibles consecuencias son desconocidas, esto es, hay alguna consecuencia para la cual no sabemos si su probabilidad es cero o no-cero, lo que significa que no tenemos una lista completa de las consecuencias que debieran tomarse en cuenta -"toma de decisiones bajo posibilidades desconocidas"-. La cuestión en este tercer punto es la de cómo discriminar las consecuencias inciertas importantes de aquellas que no lo son (Hansson ctd en Rodríguez, 2003: I43).

Nos enfocaremos solo en el tercero debido a que contiene aspectos problemáticos que inmiscuyen el presente análisis.

Creemos que también podemos apoyarnos en el concepto de "riesgo desconocido", el cual no tiene una distribución conocida de probabilidades esperadas. Situación a la que se enfrentan los protagonistas del cuento señalado y que es el detonante de la incertidumbre. Estas particularidades que constituyen la incertidumbre son las que se tomarán como base para trasladar el término hacia el análisis propuesto.

Si lo anterior nos señala que podemos sondear o hacer un tipo de previsión de los posibles escenarios a los cuales nos podemos enfrentar, pero que desconocemos las posibilidades de su concreción, entonces, al enfrentarnos en este estado de toma de decisiones, nos encontramos en una condición ignorante en cuanto a la probabilidad de que ocurran, o que simplemente no ocurran. Estamos inmersos en un espacio de inseguridad y desequilibrio que también nos proyecta al azar, el "no tener una lista completa de las consecuencias" que deberíamos tomar en cuenta nos sitúa en el estado de incertidumbre.

Si retomamos entonces que varias de nuestras decisiones se realizan sin conocer las consecuencias exactas, entonces debemos de hacer supuestos especiales que nos permitan aproximarnos a las posibles situaciones resultantes. Ahora, si el conflicto con el que se enfrentan los personajes literarios los posiciona en una confrontación con el dilema, donde "las posibles consecuencias son desconocidas" y que no tengan la certeza del camino dentro de su propia historia, aquí yace la particularidad precisa que detonará 
la incertidumbre y que generará en ellos su futura toma de decisiones.

A lo anterior añadiremos los siguientes parámetros en la revisión de los cuentos y que líneas arriba son mencionados por Hannot Rodríguez: “a lo sumo enumerar los escenarios posibles..." (2003: I43) y "no sabemos si su posibilidad es cero o no-cero..." (I43); pero también nos apoyaremos en lo que menciona De Alba acerca de que la incertidumbre hay que enfrentarla "como una aventura de decisión sobre el filo de la libertad y la necesidad" (I989: 7).

De manera que las instancias que abordaremos dentro de los cuentos irán guiadas por estos señalamientos. Sucede con el extranjero de "El guardagujas", que al llegar a la estación para tomar su tren, el viejo guardavía comienza a vaticinarle todos los posibles escenarios en los cuales puede caer y que no son necesariamente el destino que indica su boleto de pasaje. El personaje del extranjero ignora cuál es el fin de su nuevo trayecto, sabe que de una u otra forma vendrá, pero ignora las circunstancias del cómo y cuándo se origine. No posee una lista de las consecuencias del viaje en el que se ha aventurado, y es esta situación precisamente, el arrojo a lo desconocido, donde: "nos conduce a un cambio de visión de la realidad" (Nieto de Alba, ı989: ı8).

\section{La incertidumbre dentro del país del guardagujas}

Como inicio se plantean algunos de los momentos dentro de la trama de "El guardagujas”, los cuales nos servirán como vía de análisis.

Cuando el extranjero llega a la estación donde abordará el siguiente tren con dirección a "T.", lo hace con una convicción y seguridad inobjetable, pues ha detallado su itinerario y sus horarios maquinalmente, sin margen de error: "está dominado por la certeza de lo que quiere y de cómo conseguirlo” (de Mora, 2Oo6: 2I). Es necesario mencionar que "El forastero llegó sin aliento a la estación desierta. Su gran valija, que nadie quiso cargar, le había fatigado en extremo. Desalentado y pensativo consultó su reloj: la hora justa en que el tren debía partir” (Arreola, 20o6: 77). El cuento presenta a un forastero que desea, a toda costa, llegar a la ciudad de "T." pues allí ha marcado su destino. En el inicio, la mentalidad del personaje es cerraday no contempla circunstancias que lo pudieran desviar de su camino original, es decir, no contempla posibilidades, ni previsiones fortuitas. Sin embargo, la circunstancia llega en forma de "Alguien, salido de quién sabe dónde, le dio una palmada muy suave. Al volverse, el forastero se halló ante un viejecillo de vago aspecto ferrocarrilero" (77).

Según el DLE el guardagujas se define como: “Empleado que tiene a su cargo el manejo de las agujas en los cambios de vía de los ferrocarriles, para que cada tren marche por la vía que le corresponde" (2018: web). Es en la figura del guardagujas donde emerge la indeterminación del forastero, ya que este "viejecillo ferrocarrilero" es pauta para redireccionar los rumbos de los personajes, además, describe algunos de los probables escenarios en los que puede llegar a caer dentro del país. Cada escenario 
ha emergido aleatoriamente sin orden y como fruto de la variabilidad con la que llegan los trenes; además, estos escenarios poseen su propia dinámica y sus propias "reglas" de convivencia. Así, por ejemplo, existe un poblado entero que se generó debido a la descompostura de un tren; entonces, los pasajeros, en común acuerdo, decidieron vivir ahí: "El resultado ha sido F., una aldea progresista llena de niños traviesos que juegan con los vestigios enmohecidos del tren” (Arreola, 20o6: 8o); “o bien, existen aquellos que viajan más despreocupados y se bajan en estaciones al azar. También están otros casos donde los viajeros mueren dentro del tren y son sepultados en vagones especiales” (79).

La figura del forastero podemos describirla como alguien metódico, objetivo y calculador. Él ha planeado maquinalmente sus tiempos y espacios y ha trazado su viaje sin margen de error, con precisión absoluta. Por otro lado, el guardagujas representa lo contrario, laexcepciónalaregla, lo subjetivo, lacircunstancia, loinciertoylas posibilidades. Si el carácter del forastero busca evitar el "error humano", el viejo ferroviario intenta introducirlo de nueva cuenta a la acción humana para mostrarle que no es omnisciente y que el conocimiento pleno del futuro es incierto. Aquí viene a colación lo que Nieto de Alba menciona: "Desde el momento en que introducimos la incertidumbre estamos abriendo el camino de la acción humana" (I989: 4I). Pero lo que señala Nieto de Alba, lejos de derrumbar planes y estrategias, las hace fuertes, tomando en cuenta una serie de consideraciones que pueden resultar más convenientes que lo planeado anteriormente. Los errores, su previsión, las alternativas que surgen para sortearlos, ayudan al individuo a crecer, a conocerse mejor, a plantear y crear posibilidades y soluciones para solventar o sortear los posibles inconvenientes en su andar.

No obstante, para el viajero, estas posibilidades latentes lo someten y abruman, siente pánico ante el resquebrajo de su idea original: "Pero yo no quiero alojarme, sino salir en tren”; “¿Está usted loco? Yo debo llegar a T. mañana mismo”; “¿Me llevará ese tren a T.?”; "Es que yo tengo un boleto en regla para ir a T. Lógicamente, debo ser conducido a ese lugar, ¿no es así?” (Arreola, 2006: 78). Para el viajero, en un principio, la idea de que se fracture su plan es inconcebible. Si él organizó su itinerario, entonces el transcurso de su viaje debe seguir su estructura planificada; no previó altercados, pues hasta en ese momento de su vida, no necesitaba opciones ulteriores. Sin embargo, al momento de introducirse al país donde habita el guardagujas, su plan comienza a derrumbarse.

El señor ferrocarrilero le advierte: "Se ve que usted ignora las cosas por completo" (Arreola, 2006: 77). Después continúa dándole algunas orientaciones sobre el proceder dentro del país:

Este país es famoso por sus ferrocarriles, como usted sabe. Hasta ahora no ha sido posible organizarlos debidamente [...]. Falta solamente que los convoyes cumplan con las indicaciones contenidas en las guías y que pasen efectivamente por las estaciones; Yo he visto pasar muchos trenes en mi vida y conocí algunos viajeros que pudieron abordarlos. [...] ¿Y por qué se empeña usted en que ha de ser precisamente a T.? Debería darse por satisfecho si pudiera 
abordarlo. Una vez en el tren, su vida tomará efectivamente algún rumbo. ¿Qué importa si ese rumbo no es el de T.?; En la fonda para viajeros podrá usted hablar con personas que han tomado sus precauciones, adquiriendo grandes cantidades de boletos. Por regla general, las gentes previsoras compran pasajes para todos los puntos del país (Arreola, 20o6: 78-79).

El guardagujas advierte al viajero de que existen bastantes posibilidades de que no concrete su plan para llegar a T., y que mejor adquiera otras opciones para que lo lleven a otros lugares. Podemos decir que el ferroviario lo está preparando para que haga frente a las disposiciones que conllevan un estado de incertidumbre, lo adentra a la formulación de alternativas:

Las posibles consecuencias son desconocidas, esto es, hay alguna consecuencia para la cual no sabemos si su probabilidad es cero o no-cero, lo que significa que no tenemos una lista completa de las consecuencias que debieran tomarse en cuenta (Rodríguez, 2003: 4I),

y el guardagujas solamente menciona algunas de estas consecuencias:

En realidad, hay muchísimos trenes en la nación, y los viajeros pueden utilizarlos con relativa frecuencia, pero tomando en cuenta que no se trata de un servicio formal y definitivo. En otras palabras, al subir a un tren, nadie espera ser conducido al sitio que desea (Arreola, 2006: 79).

Si tomamos al tren como símbolo de la vida, al subirnos en él, tomamos un camino que nos guía muchas veces a lugares a los que no habíamos planeado llegar, por ello, antes de abordarlo podemos crear o imaginar posibilidades para, en caso de contingencia, lograr solventar la situación. Si sabemos que en nuestro futuro nada tiene certeza ¿qué mejor que enfrentar estas problemáticas previendo o creando escenarios posibles? De esta manera, la incertidumbre nos ayuda a imaginar y crear alternativas para sortear obstáculos eventuales y nos auxilia a amoldar nuestra estrategia a las diferentes posibilidades que se nos puedan presentar, y de esta forma, tanto el personaje del forastero como el lector participativo, podrá enfrentar la incertidumbre "como una aventura de decisión sobre el filo de la libertad y la necesidad” (Nieto de Alba, r989: 7).

En este caso, el forastero llega con un plan rígido sin opciones diferentes, entonces se enfrenta a la circunstancia imprevista; el miedo y la confusión se apoderan de él: “-¡Dios mío, yo no estoy hecho para tales aventuras!” (Arreola, 20o6: 8o); empero, el guardavía, a través de la experiencia que ha aprendido, "sabe" que los viajeros, como en el caso del forastero, planean un único trayecto -o su vida- de manera maquinal y sin alteraciones -o emociones-, cometen el error de someterse a una vida radicalmente objetiva y pasiva, con una certeza alta de extravío. Lo que el guardagujas ha aprendido es que las personas precisamente aprenden de sus propios errores y que esto las auxiliará a elaborar predicciones para solventar sus decisiones ulteriores. Sigue existiendo el 
margen de error -Muth, Lucas y Thomas-, pero su disposición al enfrentarse con ello se transforma de un miedo frente a lo desconocido a una postura mayormente receptora ante lo incierto. Además, a través de los diálogos descriptivos que hace el guardagujas a lo largo del cuento, este fundamenta sus intervenciones en el resultado de actos pasados que ha presenciado con el resto de los viajeros, así que se basa en experiencias y expectativas pasadas de otros personajes. Lo anterior le ha enseñado que no se puede tener certeza absoluta en cualquier empresa.

Didier T. Jean menciona sobre el encuentro forastero-guardagujas lo siguiente:

Sólo a través del proceso de este diálogo entre los personajes, tan misterioso y ambiguo, es que el lector ha de entender que esta falta de comunicación inicial se debe al encuentro entre dos sistemas distintos de expectativas: uno con expectativas lógicas y el otro que lo contradice. El forastero, víctima de este encuentro, sufre las angustias de la incomprensión y la falta de comunicación que el choque de los dos sistemas produce. Su perspectiva es la del que, encerrado dentro de un sistema de hábitos mentales, censura y rechaza otras posibilidades de organización calificándolas de locura, estupidez o pesadilla (I923: I62-I63).

El resultado de este choque se convierte en una vorágine para el personaje del forastero. Este estadio que no puede controlar es el de incertidumbre, por ello, encuentra como "locura, estupidez o pesadilla", las posibilidades que el guardavía describe, pues no vislumbra en su lógica sucesos ulteriores; sin embargo, el "viejecillo" le ofrece la oportunidad de construir escenarios posibles que lo ayudarán a adaptarse a las necesidades que pudieran surgir. Esta y otras situaciones donde el obrar humano se enfrenta a lo incierto, se deben tomar como una aventura y "priva al individuo de su omnisciencia haciéndole impotente para el conocimiento cierto del futuro, pero refuerza su poder sobre la naturaleza" (Nieto de Alba, I989: 40). Al tomar este cambio de paradigma, el personaje -y lo humano- restaura y fortalece su espíritu de entregarse a la vida, no como una serie de pasos fijos e invariables, sino como una oportunidad de tomar la vida misma como si fuera un entramado que se va abriendo paso por decisiones de las cuales no tenemos certeza en que ocurran o que no ocurran -“cero o no cero" según Hannot Rodríguez-. Simplemente hay que tomarlas previendo que no siempre obtendremos lo que deseamos, pero con lo obtenido debemos vivir. Con lo anterior podemos añadir que la incertidumbre es una estancia de oportunidad, más que de extravío.

Por otro lado, cuando el guardavía hace su aparición para dar auxilio al personaje del extranjero, lo hace como un antagonista consejero, el cual logra atestiguar la "conversión” de su interlocutor de un estado absolutista "¿Está usted loco? Yo debo llegar a T. mañana mismo" (Arreola, 20o6: 78), a otro que abraza las posibilidades: 
- ¿Es el tren?- preguntó el forastero.

El anciano echó a correr por la vía, desaforadamente. Cuando estuvo a cierta distancia, se volvió para gritar:

- ¡Tiene usted suerte! Mañana llegará a su famosa estación. ¿Cómo dice usted que se llama?

- ¡X!-Contestó el viajero (Arreola, 2006: 84).

Esta escena nos da la pauta para analizar las siglas "T.", "F." y el sustantivo "X". "T.", el lugar que tanto desea alcanzar el viajero, la aldea "F.", nacida del accidente férreo, son iniciales que podemos entender como el Tiempo y lo Fortuito. Así quedaría de la siguiente manera en el lenguaje del forastero:

“-Necesito salir inmediatamente. Debo hallarme en T. (tiempo) mañana mismo"; “- ¿Me llevará ese tren a T. (“tiempo")?”; “-Es que yo tengo un boleto en regla para ir a T. (“tiempo”) Lógicamente, debo ser conducido a ese lugar”; “-Yo creí que para ir a T. (tiempo) me bastaba un boleto. Mírelo usted...; “¡Pero yo debo llegar a T. (tiempo) mañana mismo!” (Arreola, 2006: $77^{-80) \text {. }}$

Y “F." en la voz del guardavía: "La aldea F. (Fortuita o Fortuna) surgió a causa de uno de esos accidentes" (Arreola, 2006:80); "Algunas de esas amistades se transformaron pronto en idilios, y el resultado ha sido F. (Fortuita o Fortuna), una aldea progresista llena de niños... (8o).

Si T. y F. resultan iniciales, en " $X$ " al no tener punto, podemos manejarlo como sustantivo, a su vez, como el nombre del lugar a donde se dirige el forastero. " $X$ " se menciona una sola vez dentro del cuento y es para manifestar el final de la metamorfosis sufrida por el forastero3. "X", simbólicamente significa la incógnita. " $X$ " sugiere cualquier lugar del trayecto; no es una plenitud en sí, pero a la vez, señala un espacio o espacios inciertos. Puesto que no se sabe si el futuro se puede planear, el viajero, completamente persuadido, cambia drásticamente de opinión: de lo determinado pasa a lo indeterminado, abraza y se contempla en la aventura que con anterioridad rechazó con espanto. Ahora está preparado.

Con la decisión tomada, de inmediato llega el tren de las consecuencias. Al asentar el cambio y reconocer que no puede disponer de las cosas mediante estrategias predeterminadas, renace con una visión diferente. El forastero viajará en tren, o como dice Seymour Menton: "El viaje a bordo del tren de la vida sin preocuparse de la ruta que

3 Concuerdo con Didier T. Jaén (I983) en "Transformación y literatura fantástica”, que " $X$ ” se refiere al lugar a donde tiene escogido llegar el forastero, no el nombre propio del viajero. Ya sea una u otra interpretación, la analogía de ambas se juntan, pues nos referimos a la improbabilidad o a la idea nueva que surge del viajero tras la discusión con el guardagujas. 
lleva" (2004: 408). El forastero ahora es otro, ha abandonado su perspectiva cerrada y se entrega al cambio de las posibilidades. Su nuevo enfoque se aloja en una nueva postura abierta y expectante aceptando la incertidumbre como parte de su nuevo trayecto. "El tren de la vida" se presenta en el momento de desengaño del forastero. En el instante que se hace este cambio de vía, su vida comienza a abrirse paso. El verdadero viaje del forastero principia 4 .

Al apoyarnos en lo referido anteriormente y con la definición de lo que es un guardagujas, podemos acercarnos a lo que este personaje puede simbolizar dentro del cuento: el guardagujas tiene como oficio hacer los cambios de las vías de los personajes, su trabajo es persuadirlos y entregarlos a la incertidumbre de la vida, no a lo que ellos habían dispuesto. Su propósito es mostrar que los hombres no pueden llevar la delantera a la vida, puesto que el futuro es incierto.

Las personas deben transitar y experimentar su camino afrontando la incertidumbre, y el guardagujas es quien les otorga esta experiencia. Por ello, él no viaja: "no he viajado nunca, ni tengo ganas de hacerlo" (Arreola, 20o6: 83). El guardavía es el encargado de cambiar el sendero de las personas. Si descuida su trabajo, todos podrían controlar su itinerario de viaje, podrían hacer cualquier cosa que tramaran con anticipación: el guardagujas es la eventualidad no prevista, es quien recuerda a los forasteros que existe una posibilidad latente de que lo estructurado se colapse en el futuro.

Entonces, los personajes del guardagujas y el forastero participan en la trama en dos planos: como actores y como espectadores. El viejecillo ferroviario interviene de manera activa en el camino del forastero al explicarle el dinamismo de ese país; y es espectador de la transformación que va ocurriendo con su interlocutor. El forastero, al sentirse enfrentado por su antagonista, comienza a reformularse su trayecto y decide mejor tomar parte activa en este, al despojarse de su objetivo inicial y ser partícipe en una aventura. Así, sus diálogos y acciones influyen decisivamente en los actos posteriores en el personaje del forastero. Con ello se abre paso la aceptación de una vida dinámica y desafiante, en lugar de una maquinalmente adaptada y pasiva.

Juan José Arreola transporta su magia narrativa a través de las vías en "El guardagujas". Cada estación contada por el viejecillo ferroviario es una asombrosa empresa que muchos viajeros iguales o más capacitados que su interlocutor han explorado; posiblemente con una idea fija como nuestro forastero, pero invariablemente acaecidos dentro del mundo en incertidumbre.

La teoría del principio de incertidumbre nos enseña a afrontar la idea de un futuro incierto; no obstante, no nos entrega al azar y a la confusión, sino que antes nos advierte que debemos planear por anticipado, prever posibles consecuencias. Estos supuestos nos auxilian a sortear la eventualidad, precisamente, para no caer indefensos ante lo

\footnotetext{
${ }^{4}$ Carmen de Mora en su Prólogo a Confabulario definitivo menciona que uno de los mensajes que trata de darnos este cuento es el de "disfruta del viaje aunque el destino sea incierto" (2006: 20).
} 
desconocido. El estar en un estado de incertidumbre, no nos asegura el éxito, sino que nos apoya para que, cuando caigamos en lo desconocido, podamos tener posibilidades de toma de decisiones. Nos ayuda a crear e imaginar para fortalecer y construir nuestra propia aventura.

Para finalizar, dejamos un comentario de Arreola que aparece en una entrevista a propósito del cuento:

Porque "El guardagujas" procede de toda una serie de vivencias personales a partir de mi primer viaje por ferrocarril hecho en la infancia, a los seis años de edad, de Ciudad Guzmán a Guadalajara. Para mí el tren es el túnel que camina, el tren es un túnel y de ahí toda la serie de imágenes que se derivan de eso, ¿̨no? Entonces yo todavía vivo en la atmósfera de “El guardagujas", vivo en la atmósfera de la incertidumbre (Nava, 2OI9: I49). 


\section{Referancias bibliográficas}

-Arreola, J. (2006). Elguardagujas. Confabulario definitivo. Madrid: Cátedra.

-Arreola, O. (1998). El último juglar. Memorias de Juan José Arreola. México: Diana.

- Borch, K. (I968). The Economics of Uncertainty. Princeton: Princeton University Press.

- Garayalde, N. (2018). Dos problemas (y sus posibles soluciones) de la transferencia interdisciplinaria en la investigación literaria. El caso literatura/psicoanálisis. Estudios de Teoría Literaria. Revista digital: artes, letras y humanidades, Vol. 7 (г3), 99-IIо. Obtenido el I2 de octubre de 2018 desde https://fh.mdp.edu.ar/revistas/index.php/etl/article/ view/2IO9/2625

- Gil, M.; Pérez J. y Urtasun A. (20I7). Incertidumbre macroeconómica: medición e impacto sobre la economía española. Banco de España, Artículo 2/17. Obtenido el 23 de enero de 2019 desde https://www.bde.es/f/webbde/SES/Secciones/Publicaciones/ InformesBoletinesRevistas/ArticulosAnaliticos/2OI7/TI/fich/beaar7oI-art3.pdf

- Harrigan, F. (I99I). A modern Guide to Economic Thought. An Introduction to comparative schools of thought in economics. Reino Unido: Edward Elgar Publishing Ltd.

- Kliesen, K. (20I3). Uncertainty and economy. Federal Reserve Bank of St. Louis. Obtenido el 23 de enero de 2019 desde https://www.stlouisfed.org/ $\sim$ /media/files/pdfs/ publications/pub_assets/pdf/re/20I3/b/uncertainty.pdf

- Knight, F. (I964). Risk, Uncertainty and Profit. Nueva York: Sentry Press.

- Menton, S. (2004). El cuento hispanoamericano. México: Fondo de Cultura Económica.

- Nava, L. (2018). Entrevista con Juan JoséArreola en la Universidad Autónoma de Chihuahua (verano I977-I978). Cuadernos del hipogrifo. Obtenido el I5 de abril de 2019 desde http:// www.revistaelhipogrifo.com/wp-content/uploads/20I9/oI/I48-I56-I.pdf

- Nieto de Alba, U. (I989). La incertidumbre en la economía (paradigmas, tiempo y agujeros negros). Real Academia de Ciencias Económicas y Financieras. Obtenido el 23 de octubre de 20I8 desde https://racef.es/es/discurso/la-incertidumbre-en-la-economia-paradigmastiempo-y-agujeros-negros

- Pereyra, A. (2002). Incertidumbre e información. Uruguay: Universidad de la República.

- Plata, L.; Mejía I. y Accinelli E. (2009). Sobre la teoría de decisiones bajo incertidumbre de VNM: antecedentes, extensiones y el papel de la racionalidad acotada de H. Simon. Revista mexicana de economía agrícola y de los recursos naturales, Vol. 2 (3), 45-9o. Obtenido el 
7 de diciembre de 2019 desde https://biblat.unam.mx/es/revista/revista-mexicana-deeconomia-agricola-y-de-los-recursos-naturales/articulo/sobre-la-teoria-de-decisionesbajo-incertidumbre-de-vnm-antecedentes-extensiones-y-el-papel-de-la-racionalidadacotada-de-h-simon

- Polinomics. (20I7). Expectativas adaptativas. Obtenido el 4 de enero de 2019 desde https://policonomics.com/es/expectativas-adaptativas/

- REAL ACADEMIA ESPAÑOLA: Diccionario de la lengua española, 23. ${ }^{\text {a }}$ ed., [versión $23 \cdot 3$ en línea]. https://dle.rae.es Obtenido el 24 de marzo de.

- Ricœur, P. (2009). Tiempo y narración I. Trad. Agustín Neyra. México: Siglo XXI.

- Rodríguez, H. (2003). Riesgo y principio de precaución. Hacia una cultura de la incertidumbre. Revista Catalana de Seguretat Pública, Núm. ı3, ı39-I6I.

- Tisdel Jaén, D. (I983). Transformación y literatura fantástica “El guardagujas” de Arreola. Centro de investigaciones lingüisticas-literarias, Vol. 26-27, I6I-267.

-Vázquez, F. (2OI3). Cazadores de invisible. México: Fondo Editorial del Estado de México. 